\title{
TRANSPORTE INTERNACIONAL Y ACTORES SUBNACIONALES: LA PROVINCIA DE MENDOZA Y LA RESURRECCIÓN DEL FERROCARRIL TRASANDINO ENTRE ARGENTINA Y CHILE*
}

\author{
International Transport and subnational actors: the Mendoza Province \\ and the resurrection of the Transandine Railway between Argentina and \\ Chile
}

Pablo Lacoste Gargantini**

Diego Jiménez Cabrera ${ }^{* * *}$

Recibido: 31 de agosto de 2012. Aprobado: 7 de marzo de 2013.

\section{RESUMEN}

Tras un siglo de prestar servicios de transporte de cargas y pasajeros entre Argentina y Chile, el Ferrocarril Trasandino quedó desactivado en 1984. A partir de entonces, el transporte terrestre regional se realizó casi exclusivamente por la carretera de Los Libertadores. Pero el crecimiento del volumen de carga saturó este corredor y se volvió a pensar en el Trasandino como una solución. La iniciativa fue impulsada por un actor subnacional: la provincia de Mendoza. Bajo su liderazgo se volvió a poner el tema en foco, se articularon diversos actores (públicos y privados) y se diseñaron los primeros proyectos de reactivación. El artículo examina la evolución de esos proyectos, particularmente el rol de los actores principales: el Gobierno de Mendoza, el Parlamento, el Estado nacional, las corporaciones militares y el sector privado. Se destaca particularmente el papel de Mendoza como actor subnacional.

PALABRAS CLAVE: Ferrocarril Trasandino, corredor bioceánico, actores subnacionales

* Este artículo es resultado del Proyecto de investigación USACH-VRID-DICYT 031094CV, "Los efectos del populismo argentino y boliviano en la política exterior de Chile".

** Universidad de Santiago de Chile, Instituto de Estudios Avanzados IDEA, Santiago, Chile. Correo electrónico: pablo.lacoste@usach.cl

*** Universidad de Santiago de Chile, Programa de magíster, Instituto de Estudios Avanzados IDEA, Santiago, Chile. Correo electrónico: djc.intothefi re@gmail.com 


\begin{abstract}
After a century of providing transportation of cargo and passengers between Argentina and Chile, the Transandine Railway was deactivated in 1984. Following this action, regional ground transport was done almost exclusively through the Los Libertadores Highway. But the growth and volume of cargo transported saturated this corridor and the Transandine Railway began to be reconsidered as a solution. This process was led by a Subnational Actor: the Province of Mendoza. The article examines the evolution of this project in its political context, particularly the role of the main actors: the Government of Mendoza, the Parliament, the National Government, military corporations and the private sector. This paper emphasizes Mendoza's role as a subnational actor.
\end{abstract}

KEYWORDS: Transandine Railway, Bi-Oceanic Corridor, subnational actors

\title{
I. INTRODUCCIÓN
}

A lo largo de buena parte del siglo XX, el Ferrocarril Trasandino fue el principal medio de transporte bioceánico del Cono Sur de América. Su construcción fue una de las grandes obras de ingeniería del continente en su momento. Aprobado por Ley $\mathrm{N}^{\circ} 583$, de 1872, se libró al servicio en 1910 para unir Argentina y Chile a través de la cordillera de los Andes. La colosal obra incluía 240 kilómetros de vías férreas de alta montaña, con numerosos puentes, túneles y otras obras de arte. A partir de entonces, se produjo un importante salto en las relaciones económicas, sociales y culturales no solo de los dos países, sino de toda la región (Lacoste 2000; Thomson 1997; Thomson y Angerstein 1997). Posteriormente, las energías se orientaron hacia el transporte automotor y la carretera, y el Ferrocarril Trasandino fue quedando obsoleto, hasta dejar de funcionar entre 1979 (pasajeros) y 1984 (cargas). Las instalaciones del antiguo ferrocarril quedaron abandonadas como parte del paisaje cordillerano, al parecer, para siempre.

De todos modos, en pocos años, la infraestructura vial se reveló insuficiente para satisfacer la demanda de transporte. El crecimiento económico de la región y de la cuenca del Pacífico (particularmente el auge de China), generaron un nuevo contexto de mayor demanda de intercambio comercial. La diplomacia contribuyó a facilitar la circulación de cargas mediante los Acuerdos de Complementación Económica, sobre todo el ACE 16 (firmado por Argentina y Chile en 1991) y el ACE 35 (acordado entre Chile y el Mercosur en 1996). El volumen del comercio trasandino experimentó una expansión sin precedentes y la carretera por Libertadores quedó colapsada con un flujo diario de 1.000 camiones 
de carga. Fue necesario buscar soluciones complementarias y poco a poco, las circunstancias se hicieron cada vez más propicias para la resurrección del Ferrocarril Trasandino.

Las demandas del transporte se encontraron con obstáculos políticos. El propietario de la mayor parte de la línea, el Estado argentino, carecía de recursos económicos y culturales para afrontar el problema. Los antecedentes del Estado como administrador de los ferrocarriles en Argentina eran bastante negativos: en 40 años, la empresa de ferrocarriles del Estado fue conducida por 20 directorios distintos. La situación se agravó en la década de 1990, cuando las políticas neoliberales profundizaron el abandono del patrimonio ferroviario nacional; a ello siguió la crisis del 2001 y el decenio populista posterior, signado también por la desinversión en obras y servicios públicos en general, y transporte ferroviario en particular, proceso que culminó con la "Tragedia de Once". ${ }^{1}$ En los últimos 20 años, el Estado nacional de Argentina no exhibió interés por los ferrocarriles y en estas condiciones, las perspectivas de reactivar el Trasandino eran remotas.

De acuerdo a los expertos de la Comisión Económica para América Latina y el Caribe (Cepal), la pérdida de interés estatal por los proyectos ferroviarios se debe a que estos tienden a exigir altos niveles de inversión que, en muchos casos, el Estado no se encuentra en condiciones de ejecutar por sí mismo, o simplemente no tiene interés en realizar por tres causas: a) el tipo de desplazamiento de carga que le interesa a los gobiernos es exportación más que el de importación; b) el ferrocarril ha requerido sostenidamente de la subvención estatal para seguir funcionando, más allá de la iniciativa privada que le dio origen y lo implementó, lo que generó costos de operación imputables al Estado en el largo plazo; c) los márgenes de rentabilidad de estos proyectos no consiguen captar la atención del sector privado (Thomson 2001). No obstante, proyectos de esta envergadura pueden generar beneficios intangibles que superen los resultados de las evaluaciones económica y socioeconómica desarrolladas, por lo cual se justificaría su implementación (Fontaine 2008:561-68). Para que esto último sea posible, se requieren decisores con una visión integral de lo que implica el ferrocarril para el desarrollo.

Mientras el Estado nacional orientaba su interés hacia otros temas, se generó un espacio importante para el surgimiento de los actores subnacionales que, lentamente, asumieron un papel destacado en temas internacionales, particularmente para solucionar problemas concretos en zonas de frontera. Este fenómeno fue advertido por algu-

$1 \quad$ La "Tragedia de Once" (22 de febrero de 2012) fue un accidente ferroviario en el barrio homónimo de la ciudad de Buenos Aires, con un saldo de 51 muertos y 703 heridos, en el ferrocarril General Sarmiento. Esta empresa utilizaba material rodante y de tracción obsoleto, incluyendo coches de la década de 1920, con deficientes sistemas de conducción y frenado. 
nas embajadas que, al comprobar la falta de atención de las cancillerías, encontraron interlocutores válidos en los Estados provinciales y municipales; establecieron relaciones directas e iniciaron actividades conjuntas para alcanzar objetivos comunes. En otros casos, las relaciones se establecieron también entre actores subnacionales de países vecinos (municipios y provincias). Fue una nueva modalidad de construcción de vínculos que se verificó en buena parte de América Latina, pero especialmente entre Argentina y Chile (Maira 2010).

Los proyectos de altos costos en zonas de frontera (como el caso del Trasandino) se caracterizan por la complejidad político-institucional, pues se requiere compatibilizar marcos legales, intereses socioeconómicos y políticos muchas veces divergentes. Estos desajustes pueden frustrar la ejecución del proyecto como ocurrió con el ente binacional Yacyretá, el Proyecto Hidroeléctrico Corpus Christi y la Hidrovía Paraná-Paraguay (Colacrai 2004:147-56). De allí la importancia de un centro rector que asuma el liderazgo para conectar a los actores involucrados y poner en marcha una estrategia de conciliación de intereses y construcción de consensos. En el caso argentino, dada la estructura federal de su constitución, las provincias pueden dar inicio a una acción, en forma coordinada con el Estado nacional, para alcanzar objetivos en el plano internacional (Zubelzú 2008:38-9). Sin embargo, en aquellos casos en que la acción del Estado central (o su omisión) dificulte la ejecución de proyectos estratégicos binacionales o multinacionales de una provincia, las instituciones políticas subnacionales (provincia, Congreso provincial), tenderán a ejecutar acciones tipo lobby destinadas a negociar, o bien a presionar, al Gobierno nacional para obtener recursos de este último, destinados a generar impactos relevantes en su economía (Zubelzú 2008:39). Aunque también pueden ejercer acciones de tipo lobby de modo conjunto (entre varias provincias) y acciones concertadas (con los Comités de Frontera).

Otro elemento a tener en cuenta es el papel de las Fuerzas Armadas que, desde mediados del siglo XX se vieron fuertemente influidas por las teorías geopolíticas generadas por los intelectuales del centro de Europa, que tendían a ponderar a los países vecinos como enemigos y a desconfiar de los proyectos de integración física. En el caso argentino, las Fuerzas Armadas fueron un actor constante en el sentido de bloquear inversiones de infraestructura en zonas de frontera; durante la dictadura del general Onganía, se impuso la ley de seguridad nacional, por la cual se restringía la construcción de carreteras a menos de $100 \mathrm{~km}$ de las fronteras, lo cual desactivó por muchos años la construcción de corredores bioceánicos; a ello se sumó el constante bloqueo de los proyectos de mejorar las instalaciones del Ferrocarril Trasandino por medio de electrificaciones y construcción de túneles largos de baja altura, actitudes sostenidas por los gobiernos de facto de los años 50 y 60 (Lacoste 2000:365-76). 
El presente artículo se propone reconstruir este proceso de gestiones, negociaciones y proyectos que se sucedieron en los últimos tres lustros para la reconstrucción del Ferrocarril Trasandino, con especial atención al papel de los diversos actores involucrados (estatales y no estatales, nacionales y subnacionales). Se examinan los dos proyectos (elaborados por sendas empresas privadas) y el intenso juego institucional que se desplegó entre las distintas agencias, con particular énfasis en el papel que le cupo a la provincia de Mendoza en su calidad de actor subnacional.

\section{EL DETERIORO DEL TRASANDINO Y EL ESTADO DESERTOR}

El eclipse del Trasandino coincidió con el auge del modelo neoliberal, primero en Chile durante la dictadura de Pinochet y luego en Argentina, en el gobierno de Carlos Menem. Desde la perspectiva de la historia de las ideas, se ha definido como principal característica del neoliberalismo, la demonización del Estado (Devés 2003:261-90). En este contexto, los gobiernos de ambos países pusieron en marcha una agresiva política de reducción del aparato del Estado, particularmente las empresas de servicios públicos, dentro de las cuales se encontraban las redes ferroviarias. En este proceso de reducción general del tamaño del Estado, las áreas donde se actuó con mayor energía fueron aquellas donde se consideraba que los servicios podían ser prestados por el sector privado. Este fue el caso del Trasandino que, al contarse con la alternativa del transporte automotor por las carreteras, se incluyó dentro de las áreas valoradas como prescindibles. El Estado perdió todo interés por sostener los servicios del tren de montaña.

Después de quedar fuera de servicio (1984), el Trasandino quedó abandonado a su suerte. Parte de su patrimonio fue vandalizado. Algunas instalaciones fueron desmanteladas u ocupadas ilegalmente. Se produjeron robos de durmientes y rieles a lo largo de muchos kilómetros. A la acción de los delincuentes comunes se sumó la conducta de los organismos nacionales que igual manifestaron poca sensibilidad por este patrimonio, al cual desguazaron. Además, cada vez que los derrumbes afectaban la carretera (Ruta Nacional 7, Argentina), correspondía a la Dirección Nacional de Vialidad reparar el camino para asegurar la conectividad. Pero en reiteradas oportunidades, la solución implementada consistía en el recurso más fácil: invadir la traza del Trasandino y construir sobre ella. Estas acciones se sumaron al deterioro social y natural de la vía, para afectar sensiblemente, las instalaciones del antiguo ferrocarril de montaña. El resultado fue notable: en pocos años de desuso, el Trasandino sufrió un deterioro comparable con el daño causado por el aluvión de Cacheuta en 1934. 
Esta situación contrastaba con lo que ocurría del lado chileno. De los $70 \mathrm{~km}$ de extensión de la línea ferroviaria, casi la mitad se mantuvo en uso y buenas condiciones. En efecto, los chilenos lograron preservar en actividad el Ferrocarril Trasandino para el tramo de 30 kilómetros entre Saladillo y Los Andes. Se aprovechó la infraestructura del trazado para mantener un servicio regular de transporte de carga, particularmente orientado a la producción minera de la División Andina de Codelco, emplazada en Saladillo, cerca de la estación Río Blanco. Como resultado se logró conservar en buenas condiciones casi la mitad de la infraestructura de la sección chilena del Trasandino, situación vigente hasta la actualidad.

El desmantelamiento de las instalaciones de la sección argentina del Trasandino se produjo con el consentimiento de su propietario, el Estado nacional. Este era el titular y responsable del Trasandino desde la sanción de la ley de nacionalización (1939). En una primera etapa, el Gobierno nacional manifestó interés y realizó fuertes inversiones en esta línea. En pocos años logró reconstruirla y librarla nuevamente al servicio (19391943). Durante las siguientes tres décadas, el Trasandino prestó servicios internacionales de transporte de carga y pasajeros, hasta que, entre 1979 y 1984, este ramal quedó fuera de servicio en el marco de la profunda crisis del sistema ferroviario argentino. Este proceso culminó en 1989 cuando el presidente Carlos Menem dispuso el cierre de algunos ramales y la privatización de otros. El Trasandino quedó entre los desactivados.

La transferencia de los ramales ferroviarios del Estado nacional a los Estados provinciales fue la culminación de este proceso. En la década de 1990, el gobierno central avanzó en esta dirección, con resultados disímiles. El ramal a Jáchal, del F.C. Belgrano, fue transferido a la provincia de San Juan. Durante su gestión, el ramal fue descuidado, desmantelado y vandalizado. En pocos años, solo quedó lo que era imposible robar: terraplén, estaciones y algunos puentes y tramos de vía. Hubo asimismo transferencias con resultados positivos, sobre todo en Río Negro y Chaco. ${ }^{2}$ En este contexto se produjo el traspaso provisional del Trasandino a Mendoza.

En efecto, en 1994 se firmó un comodato por 30 años, por el cual el Estado nacional cedió el Trasandino a la provincia de Mendoza. A partir de entonces, la provincia quedaba como responsable de la línea. Al frente del gobierno se encontraba el Partido Justicialista, liderado por el gobernador Rodolfo Gabrielli. Esta administración provincial estaba alineada políticamente con el menemismo, corriente de orientación conservadora y con escaso interés por la cultura ferroviaria. De todos modos, el gobierno de Mendoza no compartía la adhesión automática del gobierno nacional a la ideología neo-

2 Nota de Pablo Anglat (Mendoza, 5 de octubre 2010). 
liberal, que se había proclamado enemiga de los trenes por su carácter deficitario. El gobierno de Mendoza tenía algunos matices, a través de los cuales se dejó espacio para cierta preservación de los ferrocarriles. Esta situación se iba a hacer visible con motivo de la construcción del dique Potrerillos.

\section{EL DIQUE POTRERILLOS Y LA “INVENCIÓN” DEL TRASANDINO}

El redescubrimiento del Trasandino se produjo en forma indirecta, en el marco de la construcción de una de las grandes obras públicas de Mendoza de las últimas décadas: el dique embalse Potrerillos. El objetivo era regular el río Mendoza, ampliar la superficie cultivable, generar energía hidroeléctrica y promover el turismo. Se trataba de un antiguo proyecto provincial, formulado en 1919 durante la gestión del gobernador José Néstor Lencinas. Fue reactivado durante los gobiernos de Carlos Washington Lencinas (19221924) y Santiago Felipe Llaver (1983-1987). Hasta que finalmente, la iniciativa se puso en marcha durante la gestión del gobernador Arturo Lafalla (1995-1999).

El proyecto dique Potrerillos fue una de las grandes obras públicas de Mendoza en el último siglo. Las obras comenzaron en enero de 1999 y la inauguración se realizó a fines de 2001, tal como estaba previsto. Fue la única obra de envergadura que se hizo en la Argentina en la década de 1990 (Lacoste 1998:129-34; Lafalla 2010:290-94).

La construcción del dique Potrerillos puso al Trasandino en foco. Sobre todo porque, para ahorrar costos, eligió como lugar para construir el muro de contención del río Mendoza, en la parte más encajonada, es decir, en Cacheuta. De esta manera, la obra interrumpía e inundaba un tramo importante de la infraestructura de transporte terrestre que conectaba Mendoza con Chile, tanto la ruta internacional № 7 como las vías del Trasandino. La novedad causó un fuerte impacto, en especial por el corte de la carretera: el dique Potrerillos significaría interrumpir el principal ducto de transporte terrestre de cargas bioceánico del Mercosur. Tras realizar los estudios del caso, los ingenieros resolvieron solucionar el problema mediante la construcción de una nueva traza de la Ruta 7, paralela a la anterior, pero en la margen derecha del río Mendoza, unos kilómetros al sur, rodeando el cerro Cacheuta por el sur, pasando por el parque Petroquímico Luján de Cuyo. Esta nueva traza de la Ruta 7 se llamaba generalmente "Variante por Destilería".

La relación entre el dique Potrerillos y las obras indirectas era un tema crítico. En la Facultad de Ciencias Económicas de la Universidad Nacional de Cuyo se formó un 
equipo de expertos en formulación y evaluación de proyectos de inversión, liderado por Coloma Ferrá y Roberto Cortegoso. Este organismo dimensionó los costos de la Variante por Destilería y sobre esta base, dictaminó que, en caso de incluirse este monto dentro del costo general del dique Potrerillos, la evaluación económica de la obra resultaba negativa. Por lo tanto, la única forma de tornarla viable era mediante la exclusión. El Gobierno de Mendoza tomó la decisión política de avanzar en esta dirección. Así se reflejó, finalmente, en el contrato firmado con la empresa constructora (CEMPPSA), mediante la inserción de un párrafo referido a "tópicos pendientes" de los que debería en forma y tiempo oportuno hacerse cargo el Estado provincial. Las obras de la Ruta 7 se pusieron en marcha un tiempo atrás de las del dique y, pocos años después, se libraba al servicio la nueva carretera.

Nadie imaginaba que, solucionado el problema vial, quedaría pendiente la situación del Trasandino. Desde el punto de vista jurídico, correspondía hacer con el ferrocarril lo mismo que con la carretera, es decir, incluir el traslado de la traza dentro del costo general de las obras colaterales o "tópicos pendientes" a las del dique Potrerillos. Sin embargo, los contadores importados para tal fin se opusieron terminantemente a esta idea. "No podemos pagar por un ferrocarril inexistente que va hacia ninguna parte", 3 sostenían en las rondas de negociación.

En este contexto se produjo el giro de la situación. El entonces gobernador de Mendoza, Arturo Lafalla, detectó el valor estratégico del Trasandino. El tempus no era favorable para ello porque la construcción rápida del dique Potrerillos era una necesidad política prioritaria y el Trasandino podía ser un obstáculo para ello. Sin embargo, Lafalla intuyó que allí había algo con potencial, y resolvió actuar en esa dirección. Este fue el sentido del nombramiento del ingeniero Marcelo Rogé como miembro del equipo de gobierno del Ministerio de Obras Públicas y Ambiente. La provincia de Mendoza empezaba a posicionarse como actor subnacional al incorporar en su agenda el desarrollo de un medio de transporte internacional (el Ferrocarril Trasandino).

\section{LA PROVINCIA DE MENDOZA COMO ACTOR SUBNACIONAL}

La provincia de Mendoza pudo actuar como actor subnacional porque se dio una política de Estado en el tema de la reactivación del Trasandino, la cual fue sostenida por distintas administraciones. Pudieron cambiar los gobernadores, pero el equipo encargado del tema se mantuvo en sus puestos. Nombrado por Lafalla, Rogé fue confirmado

3 Referencia del ingeniero Marcelo Rogé al autor. Entrevista personal, Mendoza, 20 de agosto de 2010. 
en el cargo por sus sucesores, los gobernadores Roberto Iglesias y Julio Cobos. Como resultado, Rogé se mantuvo en el puesto durante casi una década (1998-2007), situación muy rara en la política argentina. Esto último favoreció particularmente al Trasandino, pues mediante una sucesión de acciones concretas, la provincia se consolidó como actor subnacional, y logró llenar el vacío dejado de hecho por la Nación.

La acción del Estado provincial sobre el Trasandino se visualizó en dos aspectos fundamentales: preservar el patrimonio e impulsar estudios para su reactivación. Las instalaciones comenzaron a cederse en comodato a los interesados, para que estos asumieran la responsabilidad de cuidarlas. Así, por ejemplo, la estación de Penitentes (km 151) se concesionó a una empresa joven que montó allí el Mundo Perdido, una iniciativa cultural de venta de artesanías y museo interactivo. En la estación Potrerillos se instaló la sede de la biblioteca popular Armando Tejada Gómez (1994). Este centro cultural se había fundado dos años antes en una casa particular, propiedad de una humilde vecina de esa localidad. Luego se realizó un acuerdo para que la estación del Trasandino se transformara en sede de la biblioteca; como contraprestación, los bibliotecarios se comprometieron también a ofrecer servicios de información turística. De este modo se puso en marcha un singular proceso de preservación del patrimonio ferroviario con su refuncionalización para crear un auténtico espacio cultural, donde se realizaban exposiciones de fotografías, arqueología, pintura y de ferias artesanales (Cunietti 1996:108-9). Con la construcción del dique Potrerillos, el área de emplazamiento de esta estación quedó dentro del perímetro del futuro embalse. Por lo tanto la sede ferroviaria quedaría bajo el agua. Se produjo entonces la movilización de otros actores de la sociedad civil, principalmente el Ferroclub Trasandino de Mendoza y otras agrupaciones, tomaron a su cargo la tarea de salvar la estación. Esta fue desmantelada, piedra por piedra, y adecuadamente guardada en cajas, con la indicación exacta del lugar que cada pieza debía ocupar en la reconstrucción. De esta manera se preservó, intacta, la estación completa del Trasandino en Potrerillos.

Además, se reactivaron los estudios sobre la factibilidad de reactivación del servicio, a la vez que se pusieron en marcha las gestiones oficiales para instalar el tema a nivel provincial, nacional e internacional. El Trasandino ya había comenzado a existir nuevamente en el horizonte mental del Estado provincial que, al involucrarse en un proyecto internacional, asumía el papel de actor subnacional. Para ello era necesario convocar a otros sectores, dentro y fuera del país. El primer paso fue concertar con el entonces subsecretario de Infraestructura, ingeniero Daniel A. Massi, el análisis de la posible reactivación del transporte de cargas internacional. Para avanzar en esa dirección, ambos organizaron una avanzada estratégica en Santiago de Chile. A través del contacto de sus colegas 
y amigos consultores de Codelco de Chile (Jünemann Hille), en enero de 1999, Rogé mantuvo entrevistas con autoridades del Ministerio de Transportes y Telecomunicaciones chileno, principalmente con el ingeniero Carlos Gárate Sánchez, entonces director de Planeamiento Estratégico y su equipo de colaboradores. En dichas entrevistas se transmitió la inquietud de realizar en forma binacional un estudio evaluativo de las factibilidades técnicas y económicas de recanalizar el flujo del transporte internacional por este recurso ferroviario abandonado y en tantas partes del mundo utilizado. Paralelamente mantuvo reuniones con las autoridades de la provincia de Los Andes (su gobernador Luis Henríquez Leiva) como con las autoridades del Consulado argentino en Valparaíso (Javier Sanz de Urquiza) y con el agregado comercial de la Embajada argentina en Santiago (Fernando R. Lerena), quienes adhirieron entusiastamente a la idea del Gobierno de Mendoza. Luego se sumaron el presidente de Ferrocarriles del Estado de Chile, Nicolás Flaño, el intendente de la Región Valparaíso, Gabriel Aldoney, con quienes se firmó el convenio inicial que concretaría la forma de realizar en conjunto los trabajos para una eventual licitación internacional y concesionar el trazado ferroviario desde Mendoza a los puertos de la Región de Valparaíso.

Paralelamente al frente político-diplomático, el Estado provincial procuró avanzar también en los aspectos técnicos. Para ello se estableció un diálogo de cercanía con los otros protagonistas de esta trama: el empresario Alberto Díaz Telli, titular de la empresa Tecnicagua y su equipo técnico, quienes realizaron los estudios de factibilidad y de inversión, tanto en Chile como en Argentina. Sobre la base de Tecnicagua se buscaron socios chilenos y en 1999 surgió la empresa binacional Ecocargas, en la cual cupo un papel relevante al ex embajador de Chile en Japón y Argentina Eduardo Rodríguez Guarachi. Además de su experiencia diplomática, este último contaba con una reconocida trayectoria como abogado asesor de empresas chilenas interesadas en invertir dentro de Argentina. Tenía su propia visión sobre el futuro de Chile: consideraba que, para transformarse en un país desarrollado, el camino era convertirse en una especie de Singapur de América del Sur, en el sentido de representar una poderosa plataforma de negocios e intercambio comercial (Rodríguez 2006). Se puso en funcionamiento una maquinaria de tres vértices, representados por el Estado (Rogé), el sector privado (Díaz Telli) y el sector técnico (un equipo de entre 15 y 20 profesionales, contratado por Tecnicagua). El grupo empresario solicitó y obtuvo un marco jurídico de lineamientos y directrices, llamado "Términos de referencia", aportados por el Gobierno de Mendoza (por entonces "concesionario" del Trasandino) y el Gobierno de Chile en el marco del Grupo Técnico Mixto de ambas cancillerías. 
Las gestiones entregaron su primer resultado concreto: un anteproyecto de reconstrucción ferroviaria que era técnicamente factible y económicamente viable. Este se formalizó en octubre de 1999, cuando el Comité Ejecutivo para la Concesión de Obras y/o Servicios Públicos de la Provincia de Mendoza, aconsejó la aprobación de la propuesta de estudios conjuntos para la reactivación ferroviaria trasandina, recibida en agosto de manos del empresario Alberto Díaz Telli; en los términos de la Ley provincial 5507 de concesiones de obras y servicios públicos por iniciativa privada.

\section{EL TRASANDINO Y EL NUEVO PROYECTO DE REACTIVACIÓN}

El trabajo impulsado por Ecocargas se proponía alcanzar un objetivo de mínima: poner nuevamente en funcionamiento el Trasandino, con los menores costos posibles. La idea era empezar de menos a más. Para avanzar en esta dirección, se trazó un plan que apuntaba a aprovechar al máximo la infraestructura existente, con la menor inversión, de modo tal de hacer viable el proyecto en la realidad. Una vez puesta la línea en funcionamiento y demostrada su capacidad y potencial, se podrían incorporar obras complementarias que, poco a poco, permitieran disponer de un recorrido más suave, con menos pendientes, curvas más abiertas y mejores prestaciones. El objetivo estratégico principal era volver a enlazar el tren con la cordillera; redescubrir la montaña y la forma de vincularse con ella de la forma más amigable posible, desde la perspectiva ferroviaria. Comenzar, paso a paso, a construir de nuevo la cultura del ferrocarril de montaña.

El objetivo era reactivar el trazado del ferrocarril Trasandino que los hermanos Juan y Mateo Clark habían planteado en el último tercio del siglo XIX. Se mantenían los aspectos esenciales como la trocha angosta y la mayor parte de la traza. El único cambio importante era el trazado nuevo a relocalizar por el embalse en Potrerillos. Estas obras se ubican geográficamente en los Andes centrales, cuyo trayecto está definido por la quebrada del río Mendoza, en su mayor extensión, y por el río Cuevas, en la República Argentina. En tanto en el sector chileno por la quebrada del río Aconcagua hasta Los Andes, punto final de la intervención propuesta. La problemática más compleja de este antiguo trazado es el perfil altitudinal de este paso; se materializa desde los 800 metros sobre el nivel del mar en la ciudad de Mendoza, llegando a los 3.100 metros en la localidad de Las Cuevas, Argentina, y bajando abruptamente hasta los 800 metros en la localidad de Los Andes, República de Chile. Era necesario restaurar las instalaciones de los dos lados, ambas dañadas por el abandono. Ya se ha mencionado la situación de la sección argentina; pero la chilena se encontraba en un estado parecido. Sobre todo por la destrucción com- 
pleta del tramo comprendido entre la frontera y Saladillo. Ello demandaba reconstruir aproximadamente $42 \mathrm{~km}$ de vías.

El equipo de trabajo recorrió la totalidad de la línea entre Mendoza y Los Andes. Examinó cada kilómetro de vías férreas, cada obra de arte, cada puente y cada túnel. También elaboró un inventario de las estaciones y demás elementos de las instalaciones y equipamiento del Trasandino. Sobre esta base, se hizo el estudio de las obras necesarias para reactivar el servicio. Después de varios años de trabajo, se llegó a una cifra de 220 millones de dólares. Este resultado obtuvo el aval tanto de las autoridades del Gobierno de Mendoza como de Chile, con los correspondientes fundamentos técnicos aportados por Ecocargas. La idea era llamar a licitación pública para ofrecer el proyecto mediante licitación de obra privada. En este concurso se podía presentar la empresa Ecocargas como un oferente más. En caso de ser vencida por una propuesta mejor, esta debía pagarle una compensación por el monto invertido en los estudios. Sobre la base de estos criterios, se avanzó.

\section{EL TRASANDINO VUELVE AL CONGRESO DE LA NACIÓN}

El liderazgo de la provincia de Mendoza en la valoración del Trasandino tenía un lado débil. En efecto, Mendoza se había hecho cargo de este ferrocarril en 1998, ante el abandono ostensible del Estado nacional. Por lo tanto, tenía una legitimidad sobre el mismo, ganada a fuerza de trabajo y dedicación. Sin embargo, desde el punto de vista legal, la línea seguía siendo propiedad de la Nación. Para superar esta inconsistencia, el diputado Francisco García (Partido Justicialista-Mendoza), acompañado por su par Víctor Fayad (Unión Cívica Radical-Mendoza) presentó un proyecto en el Congreso de la Nación, por el cual se perfeccionaba jurídicamente el traslado de propiedad del Estado a la provincia de Mendoza:

LEY 25.472

ARTÍCULO $1^{\circ}$.- Transfiérense a favor de la provincia de Mendoza, los ramales ferroviarios, individualizados como ramal "A 12", que vincula las localidades de Mendoza y Las Cuevas, desde el kilómetro 1072,245,70 al kilómetro 1259,549 y el ramal "A 16", que vincula las localidades de Mendoza y Luján de Cuyo, desde el kilómetro 1099,161,2 hasta la estación Paso de Los Andes del ramal "A 12", ambos de la ex línea General Belgrano, conjuntamente con los inmuebles, depósitos y bienes que por 
accesión legal integran los ramales que por la presente se transfieren, al igual que los terrenos que ocupan las vías de los ramales "A 12" y "A 16".

ARTÍCULO $2^{\circ}$.- La provincia de Mendoza, una vez finalizadas las tareas referidas a las obras correspondientes al “Aprovechamiento integral del Río Mendoza” -Proyecto Potrerillos-, aprobadas por ley provincial $\mathrm{N}^{\circ} 6560$, y que se efectúan sobre el sector inactivo del ramal "A 12", que por la presente se transfiere, llamará a licitación pública a los efectos de reempalmar, relocalizar y/o restaurar, el ramal afectado a fin de asegurar la explotación ferroviaria, entre la estación Paso de los Andes (km 1094,2) y la estación Las Cuevas (km 1259,5).

ARTÍCULO $3^{\circ}$.- Dentro de los sesenta (60) días de promulgada la presente ley, la autoridad de aplicación procederá a otorgar los instrumentos legales que permitan formalizar la transferencia de dominio dispuesta por la presente ley.

El proyecto ingresó a la Cámara de Diputados. Tomó formalmente estado de “Trámite parlamentario" el 8 de abril de 1999. Durante un año y medio durmió en los cajones, sin obtener dictamen de comisión. Pero logró respaldo para ser tratado sobre tablas, en la sesión del 19 de octubre del 2000. Una semana después ingresó formalmente al Senado (25 de octubre). Allí volvió a quedar detenido por un buen tiempo, ante la indiferencia de los legisladores. Hasta que casi un año después, la iniciativa logró dictamen de comisión el 12 de setiembre del 2001. Por fin quedó habilitada para ser tratada formalmente en el recinto, en la sesión de tablas.

El debate sobre la nueva ley del Trasandino, se produjo en un contexto de aguda crisis económica nacional. El país se encontraba al borde del colapso económico, con problemas de sobreendeudamiento, hiperdesocupación (25 por ciento de desocupados y 24 por ciento de subocupados), y con más de 20 monedas diferentes, entre nacionales y provinciales, proceso que culminaría dos meses más tarde con la caída del presidente De la Rúa. En ese contexto, el interés que los parlamentarios brindaron al Trasandino fue mínimo. El proyecto se aprobó en el recinto sin debate (Senado de la Nación 2001).

La sesión tuvo un costado positivo. Después de tantos años de abandono, el Estado nacional se reivindicaba. Reconocía sus errores, su desinterés, su incapacidad y su ausencia. Tácitamente, el Senado reconoció el papel que, en los hechos, había realizado la provincia de Mendoza para preservar y reimpulsar el Trasandino. La Ley 25.472 fue el perfeccionamiento jurídico de una situación que se había planteado mediante la acción real y efectiva de los mendocinos. A partir de entonces, el Trasandino quedaba en ma- 
nos de Mendoza y su política de Estado. En el marco de la crónica inestabilidad política argentina, la isla cuyana generaba un escenario relativamente calmo y confiable para dar continuidad a los proyectos. Con esta ley se fortalecería el papel de Mendoza como actor subnacional, con capacidad de tomar decisiones de efectos internacionales. Faltaba poco, muy poco, para que el país se hundiera en la anomia y el récord de tener cinco presidentes en una semana. Ya se aproximaban los días críticos de diciembre del 2001. Para atravesar esas aguas turbulentas, el Trasandino había logrado subirse a un bote relativamente estable y seguro en brazos de la provincia de Mendoza.

Las promisorias expectativas que despertó la Ley 25.472, no tardarían en frustrarse. Entre los pliegues del Estado apareció un viejo y conocido adversario del Trasandino. Ya había tenido oportunidad de hacer sentir sus efectos en 1956, 1966 y 1976, cuando suprimió las medidas tomadas por los gobiernos civiles para modernizar el Trasandino. Igual que entonces, se levantó el actor militar. Celoso de sus tradicionales valores de desconfianza con los Estados vecinos; fiel a sus enfoques geopolíticos, las Fuerzas Armadas vieron con alarma esta ley y se propusieron vetarla. Así lo plantearon al presidente Fernando de la Rúa mediante el Expediente 1383/2001 del Ministerio de Defensa (Ministerio de Defensa 2001a).

El Ministerio de Defensa solicitó vetar la Ley 25.472 mediante un argumento notable: se sostenía que, al traspasarse el ramal del F.C. Trasandino de la Nación a la provincia de Mendoza, se afectarían propiedades del Estado nacional que se habían entregado al Ejército argentino. La solicitud se fundaba en un dictamen de la Dirección de Construcciones del Estado Mayor General del Ejército, el cual:

Manifestó que el ramal A 12 atravesaba o lindaba con inmuebles que tiene asignados en uso. A tal punto, que en dichos inmuebles se encuentran los cuarteles de campo de instrucción de Uspallata y los refugios de tropas de Las Cuevas, general San Martín y general Las Heras. Esa Dirección manifestó verbalmente la inconveniencia y grave perjuicio que la sanción de ese proyecto acarrearía a la Fuerza, en razón de que la existencia y mantenimiento de los elementos citados reviste capital importancia para la defensa nacional, debiendo remarcarse que no han sido declarados innecesarios a los fines militare (Ministerio de Defensa 2001b).

En la realización de la presente investigación se revisaron los antecedentes del caso, para detectar si existían pruebas que sustentaran esa afirmación del Ministerio de Defensa. Se revisó el Expediente 1.383, y se descubrió que ningún organismo del Ejército presentó documentos para demostrar que las Fuerzas Armadas fuesen propietaria 
de algún tramo del Ferrocarril Trasandino ni de sus estaciones ni depósitos. También se solicitaron otros antecedentes al Ministerio de Defensa; pero este organismo no pudo exhibir ningún documento complementario. Por lo tanto, se concluye que la solicitud de veto de la ley, formulada por el Ministerio de Defensa, carecía de fundamentos jurídicos. Había, entonces, otras intenciones o móviles ocultos.

Los autores de esta propuesta no se atrevieron a invocar enfoques geopolíticos ni de seguridad nacional, como habían sostenido durante buena parte del siglo XX. En vez de ello, se limitaron a mencionar un obstáculo muy menor, que resultaría suficiente para alcanzar sus objetivos. Y tuvieron la audacia de afirmar que parte de las propiedades del F.C. Trasandino estaban en poder del Ejército, lo cual carecía de fundamento jurídico alguno. En todo caso, podría tratarse de alguna usurpación de terrenos y bienes del Trasandino, realizada de hecho por la corporación militar.

El expediente del Ministerio de Defensa y la solicitud del veto fueron conocidos en Mendoza, donde se desencadenó el debate. El tema fue abordado por las autoridades del Gobierno provincial y discutido con los jefes militares con asiento en la provincia. Después de debatir el fondo de la cuestión, los militares debieron admitir que los fundamentos sostenidos por el Ministerio de Defensa eran débiles y carecían de toda consistencia. Así lo reconoció el coronel Ricardo Guiñazú, segundo comandante del Comando de Brigada de Montaña VIII, con asiento en Mendoza. Después de los citados debates, y a pedido del ingeniero Rogé, Guiñazú elaboró un documento en el cual consignaba, categóricamente, que en la traza del Ferrocarril Trasandino "no existen situación de interferencia, superposición y/o coincidencia para con los inmuebles pertenecientes al Estado Nacional, bajo administración y uso por parte del Ejército Argentino" (Guiñazú 2001). Este documento iba en la misma dirección que otro, obrante en el Expediente 1.383, por el cual, el comodoro José Fernando Flores, director general de administración financiera, informó al contador Alberto García, del Ministerio de Defensa, que "el predio a que hace referencia el proyecto de ley 25.472 no se encuentra asignado en uso a esta fuerza" (Ministerio de Defensa 2001c). De esta manera se derrumbaba el último obstáculo que la corporación militar sostenía para neutralizar la ley. Mientras tanto, los días seguían corriendo y se vencía el plazo del Poder Ejecutivo para vetarla.

Se produjo entonces una carrera contra el tiempo. En Buenos Aires, los militares presionaban a De la Rúa para obtener el veto a la ley. En Mendoza, el gobierno reunía documentos y antecedentes para tratar de neutralizar la maniobra de los uniformados rioplatenses. El 22 de noviembre, el coronel Guiñazú formalizó su documento de refutación de la propuesta del Ministerio de Defensa. Ese mismo día lo entregó al ingeniero 
Rogé y el Gobierno de Mendoza lo remitió a la Secretaría General de la Presidencia de la Nación. El documento llegó a Buenos Aires, pero demasiado tarde: el día anterior, Fernando De la Rúa había vetado la ley. Para fundamentar esta decisión, el decreto señalaba los siguientes considerandos:

-Que por el Proyecto de Ley citado en el Visto, se transfieren a favor de la Provincia de Mendoza, los ramales ferroviarios "A-12" y "A-16" que vinculan las localidades de Mendoza -Las Cuevas y Mendoza-, Luján de Cuyo, respectivamente, ambos de la exLínea General Belgrano, juntamente con los inmuebles, depósitos y bienes que por accesión legal, integran los ramales que se transfieren.

-Que el Estado Nacional -Estado Mayor General del Ejército- es titular de dominio o tiene afectados al uso diversos inmuebles ubicados en la zona de influencia de la traza del ramal "A 12" en el tramo comprendido entre las localidades de Mendoza y Las Cuevas.

-Que en algunos de los inmuebles que el Proyecto de Ley sancionado propone transferir, se encuentran los cuarteles y campo de instrucción "Uspallata", el refugio de tropas "Las Cuevas", el refugio de tropas "general San Martín" y el refugio de tropas "general Las Heras".

-Que la existencia y mantenimiento de los citados destacamentos militares son de vital importancia para la defensa nacional y no han sido declarados innecesarios a los fines militares.

-Que la indeterminación de los inmuebles incluidos en la transferencia que se pretende realizar, y la necesidad de mantener los mencionados destacamentos militares hacen necesaria la observación del Proyecto de Ley registrado bajo el N ${ }^{\circ} 25.472$ (Decreto 1.491 Buenos Aires, 21 de noviembre de 2001).

Este documento resulta notable por reflejar, en buena medida, la calidad institucional de la Argentina y el grado de consistencia de sus anuncios. Por ejemplo, el texto afirma:"El Poder Ejecutivo Nacional elevará oportunamente al Congreso un proyecto de ley disponiendo la transferencia de los ramales". Han pasado 10 años y el gobierno no ha sido capaz de cumplir esta modesta promesa. Antes de ello, admite que los militares han realizado una usurpación, al señalar que "tiene afectados al uso diversos inmuebles ubicados en la zona de influencia de la traza del ramal". En tercer lugar, y tal como testimonian los documentos del coronel Guiñazú y el comodoro Flores, esta afirmación era falsa.

El veto a la Ley 25.472 reflejó las correlaciones de fuerza en la frágil zona de montaña, particularmente en el corredor andino. La presencia militar en ese espacio brindaba un punto de apoyo decisivo para influir en la toma de decisiones. Y esa influencia podía 
ponerse en favor del progreso y el desarrollo social, o en el lado opuesto, tal como ocurrió en Uspallata. En la década de 1940, el Estado nacional adquirió los terrenos de la Hacienda de Uspallata. Los militares solicitaron los terrenos para establecer allí sus cuarteles y los partidos políticos (radicales, conservadores y socialistas) propusieron reservar las tierras cultivables para pequeños emprendimientos socioeconómicos (agrícolas, agroindustriales, turísticos). Finalmente, el Estado nacional se decantó por la primera alternativa. Uspallata nació así como villa militarizada (1953). En compensación, las Fuerzas Armadas lanzaron un plan de desarrollo para este valle, que nunca ejecutaron. Ello determinó, a la larga, la frustración del desarrollo regional, en comparación con el mayor ritmo de crecimiento alcanzado en la falda occidental de los Andes. Mientras del lado chileno, Santa Rosa de los Andes ha experimentado un desarrollo sostenido en el último medio siglo, su homóloga del lado, Uspallata, permaneció estancada. Mutatis mutandis, se reprodujo en esta localidad la situación planteada por Winston Churchill en 1941: "Europa está ocupada por los ejércitos nazis, salvo España que está ocupada por su propio ejército". La presencia militar en Uspallata fue, de hecho, una ocupación asfixiante e inhibitoria del desarrollo territorial. Medio siglo más tarde, ocurriría lo mismo con el Trasandino: el veto de la Ley 24.482 fue una reactualización de este concepto.

En resumidas cuentas, el decreto por el cual el presidente De la Rúa fulminó el veto contra la ley del Trasandino, estaba apoyado en promesas que jamás se cumplieron, en afirmaciones falsas y en apologías de delito de usurpación de propiedad por parte de los militares. A pesar de estas irregularidades, el poder político se inclinó ante la presión de los uniformados. Una vez más, el enfoque militar, basado en la geopolítica y la seguridad nacional, triunfaba sobre el tren de la montaña. El Trasandino salía de la esfera de la provincia de Mendoza (el actor subnacional interesado en solucionar el problema del transporte internacional) y volvía a quedar en manos de la Nación, que por su crisis, no estaba en condiciones de enfrentar los problemas internacionales.

\section{EL TRASANDINO DESPUÉS DE LA CRISIS DEL 2001}

Un mes después del veto presidencial, en diciembre de 2001 se produjo el derrumbe del gobierno de Fernando de la Rúa. En el marco de una crisis profunda, el Presidente renunció a su cargo, mientras el país se hundía. De acuerdo a la ley de acefalía, correspondía asumir al vicepresidente de la Nación, Carlos "Chacho" Álvarez. Pero este había renunciado, con lo cual no pudo cumplir con esta función. El país se hundió en la confusión, mientras la clase dirigente nacional buscaba, desesperada, una salida. Primero se designó Presidente al gobernador de San Luis, Adolfo Rodríguez Saá, el cual tomó la 
decisión de repudiar la deuda externa argentina. El anuncio fue celebrado en el Congreso de la Nación como una victoria deportiva internacional.

Pocos días después se produjo la renuncia del efímero presidente. Siguieron nuevas vacilaciones y renuncias. Argentina alcanzó el récord de tener cinco presidentes en una semana. Las medidas de emergencia se sucedieron. Al default declarado por Rodríguez Saá, se agregó la pesificación de los depósitos bancarios en dólares, dispuesta por Eduardo Duhalde. A ella siguieron otras medidas como la brusca devaluación de la moneda argentina: para licuar los pasivos del Estado, el gobierno tomó la decisión de dejar sin efecto la ley de convertibilidad. Como resultado se salió de la paridad un peso por un dólar, mantenida durante 10 años. En pocos meses, el dólar llegó a cuatro pesos, para bajar luego y estabilizarse en tres pesos. En este contexto, reapareció el impuesto inflacionario. Después de una década casi sin inflación, los precios comenzaron nuevamente a subir, hasta superar el 25 por ciento en 2011 y 2012. El gobierno siguió tomando medidas de emergencia; entre ellas, el congelamiento de las tarifas de servicios públicos. De acuerdo a los contratos de privatización, establecidas en la década de 1990, las empresas de servicios públicos privatizadas tenían tarifas en dólares. Con esos ingresos asegurados, las firmas habían calculado que podían cubrir los costos de inversión en infraestructura, equipamiento y mantenimiento de los servicios. Pero después de 2002, la mezcla de pesificación, devaluación, congelamiento de tarifas y alta inflación, representó un cuadro complicado. Las empresas cuestionaron al Estado argentino por violar los contratos de privatización. El Estado argumentó que esas medidas se tomaron en el marco de la emergencia económica. Además, argumentó que las privatizaciones realizadas en la década de 1990 estaban signadas por la corrupción, el prevaricato y el establecimiento de tarifas abusivas por parte de las empresas.

Escapa a los objetivos del presente artículo un análisis de estos problemas. Lo importante es señalar que, durante la última década, hubo en la Argentina un ambiente de tensión entre el Estado y el sector privado. Ello se reflejó básicamente en seis elementos: a) alta inflación (hasta superar el 25 por ciento anual en 2012); b) denuncias de empresas internacionales ante los tribunales del Banco Mundial (CIADI) que, a pesar de obtener sentencias favorables, fueron ignoradas por el Estado nacional de Argentina; c) nacionalización de empresas privatizadas, sin pagar indemnización (YPF); d) caída de la inversión extranjera directa; e) fuga de capitales; f) intervención en el mercado cambiario ("cepo al dólar"). En este contexto, se complicaron las perspectivas para obtener capitales que pudieran financiar el Ferrocarril Trasandino. 


\section{EL TRASANDINO Y LOS COSTOS DE DEPENDER DE BUENOS AIRES: EL PROYECTO ECOCARGAS Y SU FRACASO}

Las posibilidades de reactivar el Trasandino dependían, en buena medida, de los costos. El incremento de estos generaba mayores dificultades para reunir fondos y de amortizar los capitales. Esta situación se hizo todavía más relevante después de la crisis del 2001, cuando Argentina quedó excluida del sistema financiero internacional. En este contexto, el diseño original del proyecto, acotado a un costo de 220 millones de dólares, tenía un valor estratégico. Para proteger este concepto, era vital mantener el Trasandino dentro de la esfera del Gobierno de Mendoza, que ha sostenido una tradición de austeridad en la administración de los fondos públicos, al menos en términos relativos con respecto a la Nación.

El veto del presidente De la Rúa significó romper el anillo de protección que Mendoza había construido alrededor del proyecto del Trasandino. El documento salió de la provincia, pasó a manos del poder central y fue sometido a las distintas reparticiones públicas nacionales, con asiento en Buenos Aires, las cuales no dudaron en incorporarle sucesivos "aportes". Por un lado, la Dirección Nacional de Vialidad exigió al Trasandino una compensación por las obras de infraestructura que esa misma entidad había realizado, usurpando el espacio y la propiedad del ferrocarril de montaña. Por su parte, Gendarmería Nacional exigió una compensación económica para construir casas del personal que había ocupado en forma ilegal las instalaciones del Trasandino en la estación Polvaredas. A ello se sumó la idea de construir un muro de seguridad que separase la carretera de la traza ferroviaria, particularmente en los tramos paralelos al río Mendoza, donde la proximidad entre ambos podía generar situaciones de peligro. Ello significó el anexo de millonarias obras colaterales -no ferroviarias- de seguridad y protección mutua entre los trazados carreteros y ferroviarios, paralelos por tramos. Como resultado, el costo de la obra subió de 220 a 320 millones de dólares.

El proyecto final comprendía los siguientes elementos: 95 millones para vías y obras en el tramo argentino; 65 millones para vías y obras en el tramo chileno, y $150 \mathrm{mi}$ llones para la adquisición del material rodante. En este ítem se incluían más de 50 pesadas locomotoras de $2.200 \mathrm{HP}$ cada una y varias decenas de vagones y plataformas portacontenedores. Con la infraestructura existente reconstruida y refuncionalizada, el Trasandino tendría capacidad para transportar hasta 3.300 .000 toneladas de carga al año. Para esto, se aprovecharían la traza existente, sus terraplenes, puentes, túneles y estaciones de cruce, manteniendo la trocha métrica en todo su recorrido, renovando vías donde es necesario. $\mathrm{Al}$ mantenerse en uso la trocha angosta, se podían aprovechar todas las obras de arte del 
antiguo Trasandino, incluyendo los gálibos disponibles en túneles y puentes. Los cálculos de los ingenieros establecían que el Trasandino estaría en condiciones de transportar contenedores de hasta tres metros de altura, 12 metros de largo y hasta 36 toneladas netas, superando con amplitud la capacidad de carga de contenedores por carretera.

Una vez puesto en marcha el servicio, el proyecto preveía un desarrollo gradual para el mejoramiento de las prestaciones. Entre otros planes, se contemplaba pasar la enrieladura de $37 \mathrm{~kg} / \mathrm{m}$ a rieles de más de $44 \mathrm{~kg} / \mathrm{m}$. También se preveía agregar un sistema de señalamiento y comunicaciones para su operación integral de última generación. En este sentido, se apuntaba a aprovechar otras oportunidades; entre ellas, los dos enlaces internacionales de fibra óptica que corren paralelos al tendido ferroviario. La idea era que el Trasandino pudiera crecer poco a poco, para satisfacer la demanda creciente, mediante mínimas inversiones en nuevas estaciones y en futuras ampliaciones del número de instalaciones de cruce. Con el gradual crecimiento de la demanda y la disponibilidad de un mayor flujo de caja, el proyecto contemplaba una ampliación sensible de la capacidad de carga. La progresión sería la siguiente: año I: 580.000 toneladas; año V: 2,8 millones de toneladas; año XII: cuatro millones y año XX: cinco millones de toneladas (Roge 2006).

Para hacer frente a los tradicionales cierres de la cordillera por acción de la nieve y los derrumbes, el proyecto consideró varios elementos. Por un lado, se estableció la construcción de falsos túneles (cobertizos) en zonas de avalanchas. Por otro, se propuso la superación de los tramos de pendientes más difíciles ( 60 por mil en el lado argentino y hasta del 80 por mil del lado chileno) mediante la incorporación de últimas tecnologías en los equipos de tracción tradicional (tándem de dos y hasta tres locomotoras de $2.200 \mathrm{HP}$ cada una). De acuerdo al proyecto, la densidad del tráfico ferroviario previsto impediría la acumulación de nieve, con lo cual sería posible mantener el servicio ininterrumpidamente. Paralelamente, para la prevención de avalanchas, y a fin de asegurar la viabilidad todos los días del año, se prevé la construcción de túneles falsos en sectores de trinchera, paso por acarreos y zonas puntuales con peligro de aludes. A ello se sumaría la prevención activa de los mismos.

Las obras principales proyectaban la construcción de $18 \mathrm{~km}$ nuevos de vía en el perilago del embalse de Potrerillos, a $40 \mathrm{~km}$ de la ciudad de Mendoza, $70 \mathrm{~km}$ de terraplenado con nuevos rieles en el sector chileno y $7 \mathrm{~km}$ de falsos túneles en el total del recorrido, conforme al siguiente detalle. En el sector argentino, las principales obras de infraestructura serían: 
1. Reparación de $153 \mathrm{~km}$ de vía en muy buen estado general, con arreglos varios en estribos y apoyos de puentes (U\$ 25.000 / km de vía).

2. Reparación de 3.500 metros de cobertizos metálicos existentes.

3. Construcción de aproximadamente 2.000 metros de cobertizos antialudes nuevos.

4. Relocalización del tramo Potrerillos:

a. Movimientos de suelos, excavación en roca $725.000 \mathrm{~m}^{3}$.

b. Colocación de vía con material (rieles y durmientes) recuperado de $17 \mathrm{~km}$ de vía cuya antigua traza quedó hoy bajo las aguas del embalse Potrerillos.

c. Colocación de balasto para nivelación y lastre $\left(10.000 \mathrm{~m}^{3}\right)$.

d. Mejoras en obras de arte menores (alcantarillas y tajeas).

e. Construcción de puentes y viaductos, reutilizando $240 \mathrm{ml}$ de puentes metálicos recuperados que fueron removidos de la anterior traza.

f. Movimientos de suelos, terraplenes $1.275 .000 \mathrm{~m}^{3}$.

g. Construcción de 520 metros de túnel en el macizo Cacheuta, el que podrá ser materializado en una sola obra continua o en dos tramos de 260 metros cada uno.

5. Construcción de talleres de vía y obras y recuperación de estaciones, playas y depósitos preexistentes.

6. Construcción de la Terminal de Intercambio de Cargas (TIC) en la Zona Franca de Luján de Cuyo. El edificio se levantaría en el predio cedido por la provincia de Mendoza de 90 hectáreas, al oeste del Parque Petroquímico Luján de Cuyo. El terminal debería servir como estación de trasbordo e intercambio multimodal de cargas, y serviría para conectar el transporte automotor de la carretera internacional con ambos sistemas ferroviarios: el de trocha métrica del Trasandino y Belgrano Cargas, y el sistema nacional de trocha ancha.

7. Sistema de señalización y comunicaciones. Ello comprende Puesto de Control de la Circulación (PCC) completo e integral para todo el corredor.

El avance de los estudios técnicos fue acompañado por la acción diplomática. Las cancillerías apoyaron el proceso y llegaron a un nivel de avance adecuado para solicitar la intervención presidencial. El 12 de septiembre de 2006 los presidentes Kirchner y Bachelet anunciaron en forma conjunta, el llamado a licitación internacional. El cronograma estableció el 21 de agosto para la apertura de sobres con propuestas técnicas, y 10 de 
octubre de 2007 para las ofertas económicas. La idea era adjudicar los contratos antes del final del 2007, para la inmediata iniciación de las obras, con un plazo de 24 meses de ejecución. El nuevo Trasandino debía librarse al servicio en la primavera de 2009. Sin embargo, la propuesta fracasó. El llamado a licitación fue declarado desierto.

El proyecto de Ecocargas se encontró con dos obstáculos insuperables: menos financiación y mayores costos. Por un lado, el contexto macroeconómico de Argentina durante la administración kirchnerista no resultaba adecuado para atraer capitales de riesgo para una obra de largo plazo. Por otro, los costos se incrementaron porque cada organismo de la burocracia nacional se sintió autorizado a exigir reformas al proyecto según sus propios intereses, lo cual fue tolerado por el gobierno: se produjo un incremento de casi 50 por ciento del valor original de la obra. Ese costo, orientado a financiar obras no ferroviarias que poco aportaban al proyecto específico, aumentó la debilidad que siempre había tenido el Trasandino: sus altos costos.

El final del proyecto de reactivación del Trasandino, impulsado por Ecocargas, se produjo definitivamente en 2007, con el fracaso de la licitación. Y este resultado se originó por dos causas principales: el incremento del costo impuesto por la burocracia central y el mal ambiente de negocios generado por las políticas populistas del gobierno nacional controlado por los Kirchner. Detrás de ambas estaban los efectos de la presión militar y el decreto 1.491, es decir, el veto a la ley de transferencia del Trasandino de la Nación a la provincia. El resultado de este veto fue perder casi una década.

\section{EURNEKIAN Y EL PROYECTO CORREDOR BIOCEÁNICO ACONCAGUA}

El fracaso de la licitación marcó el final del proyecto de Tecnicagua. Entró entonces en acción un nuevo actor, Eduardo Eurnekian, poderoso empresario con trayectoria en el ámbito del transporte internacional, titular de la empresa Aeropuertos Argentina 2000 .

En agosto de 2007, Eurnekian adquirió a Tecnicagua los derechos y estudios sobre el proyecto de reactivación del Trasandino. A partir de entonces, la iniciativa quedó en manos de la Corporación América, liderada por Eduardo Eurnekian, con la figura de Juan Manuel Collazo como responsable del proyecto. La contraparte chilena en este plan era el grupo Luksic y Petrolera del Sur. A ellas se sumaron JCCC (Argentina) y Camargo Correa (Brasil). 
La Corporación América realizó grandes modificaciones al proyecto original de Tecnicagua. Se produjo un notable cambio de escala: se abandonó la idea de un pequeño ferrocarril para 5 millones de toneladas a bajos costos y sobre la antigua infraestructura de trocha angosta. El nuevo proyecto planteó un horizonte totalmente nuevo: se pensó en un ferrocarril con 15 veces más capacidad de carga, con trocha ancha y grandes obras de infraestructura. Entre otras novedades, se pensó en construir un túnel largo de baja altura, que permitiera unir Puente del Inca con Juncal, y bajar la cota máxima del trazado, de 3.200 a 2.500 metros de altitud. De esta forma, se lograría garantizar mayor transitabilidad durante el año, pues se suprimiría el tramo de mayor vulnerabilidad por derrumbes y nevadas. Así, el costo operativo del nuevo trasandino sería ínfimo respecto al del proyecto Ecocargas.

El nuevo proyecto representaba también costos mayores. El 15 de enero de 2008 se elevó una propuesta a los gobiernos de Argentina y Chile, para impulsar la reconstrucción del Trasandino, con un costo de U\$2.810 millones. La propuesta fue considerada por el ministro de Planificación del gobierno argentino, Julio de Vido, y el ministro de Obras Públicas y Transporte de Chile, Sergio Bitar. En esta reunión se resolvió dar de baja el anterior proyecto de Ecocargas, y comenzar a considerar el proyecto de Corporación América. Esta entidad anunció la decisión de invertir U\$ 50.000.000 en los estudios de prefactibilidad. Mientras tanto, dio a conocer una cotización estimada de la obra: a) Túnel ferroviario: U\$ 1.195.000.000; b) Traza de trocha ancha: U\$ 897.500.000; c) Electrificación del ramal: U\$210.000.000; d) Autoabastecimiento de energía: U\$ 510.000.000. Entre otras características, el proyecto consideraba los siguientes elementos: a) el túnel internacional serviría para enlazar las localidades de Puente del Inca (Mendoza) con Juncal (Chile), con $24 \mathrm{~km}$ de longitud y un diámetro de 9,5 metros. La capacidad de transporte anual de carga se estimaba en 30 millones de toneladas y la fecha estimada para librarlo al servicio era en 2015.

El proyecto de Corporación América siguió avanzando. Después de una serie de reuniones con autoridades, se logró la aprobación oficial de ambos países. El Gobierno de Chile lo hizo por decreto del 14 de agosto de 2008, mientras que la presidenta argentina hizo lo propio un mes después. A partir de entonces se activaron los estudios, con un plazo estimado de dos años aproximadamente para trazar las bases del llamado a licitación de obra privada. Una vez concretada esta convocatoria, se consideraba que la obra tendría un plazo de ejecución de aproximadamente entre cinco y seis años (Galak 2008).

Hacia fines de 2010 se dio a conocer un nuevo grado de avance del proyecto, que pasó a llamarse Corredor Bioceánico Aconcagua. En efecto, el 2 de noviembre se entregó 
el estudio geológico, el anteproyecto de ingeniería y demás informes correspondientes al primer estado de avance de la Fase 2. El nuevo informe aportaba definiciones más claras de la propuesta: el nuevo Ferrocarril Trasandino permitiría atravesar la cordillera de los Andes a lo largo de un trayecto de $204 \mathrm{~km}$, desde la central multimodal Luján de Cuyo (junto al Parque Petroquímico homónimo, $20 \mathrm{~km}$ al sur de la ciudad de Mendoza), hasta la estación multimodal de Los Andes ( $80 \mathrm{~km}$ al nordeste de Santiago).

El nuevo Trasandino garantizaría el servicio los 365 días del año, es decir, evitaría los 45 días anuales de ruta cerrada por nevadas y derrumbes que actualmente sufre el corredor bioceánico por el paso Cristo Redentor. Para lograr este avance, el proyecto contempla una sensible baja de la cota máxima, que desciende de 3.200 a $2.400 \mathrm{msnm}$, lo cual implica eludir el tramo más vulnerable del corredor. Esta mejora es posible por la construcción del túnel de baja altura de 52 kilómetros, el cual sería el tercero más largo del mundo, para unir Puente del Inca $(2.435 \mathrm{msnm})$ con Saladillo (1.545 msnm). A ello se añaden 29 túneles complementarios (10 km de longitud) y 33 puentes. El costo se mantenía cerca de lo estimado anteriormente (3.000 millones de dólares).

El plazo de ejecución se ampliaba a siete años. La idea era construirlo en tres etapas, a lo largo de las cuales se ampliaría gradualmente la capacidad de carga transportada: esta partiría con 15 millones de toneladas por año (etapa 1), para subir a 20 (etapa 2) y culminar con 70 millones de toneladas (etapa 3). Los estudios de ingeniería se terminaron de realizar en la primera mitad del 2011, para ser sometidos a la última revisión técnica el 29 de julio de ese mismo año. El plazo de ejecución consideraba un tiempo inferior a una década. Así, se esperaba que el nuevo Trasandino quedara librado al servicio en 2020 (Argandoña y Poblete 2010; Balls 2011).

El proyecto de factibilidad y el anteproyecto de ingeniería se presentaron a la presidenta Cristina Fernández de Kirchner, el 26 de julio de 2011, con un costo de 25 millones de dólares. El consorcio quedó integrado por Empresas Navieras SA, Corporación América SA, Mitsubishi Corporation, Contreras Hermanos SA y Geodata SPA. Con respecto a los anuncios anteriores, se mantenía la idea de construir una línea de $205 \mathrm{~km}$ de longitud total, incluyendo el túnel de baja altura de $52 \mathrm{~km}$ de longitud y una inversión de U\$S 3.000 millones. Los túneles secundarios subían de 29 a 33, y su longitud total trepaba de $10 \mathrm{a} \mathrm{km}$. De los 33 puentes estimados anteriormente, el nuevo proyecto pasaba a 75 puentes y 33 viaductos. El servicio lo prestaría un ferrocarril eléctrico, cuya capacidad de carga subía a 77 millones de toneladas anuales. La primera etapa se calculaba completar en 2022, con una capacidad de 13 millones de toneladas anuales, para trepar a 24 millones un año después. Luego se construirá una segunda vía, en los tramos a cielo abierto, 
lo cual permitirá incrementar la capacidad de carga y llegar a 34 millones de toneladas. Más adelante, en la tercera etapa, se contempla construir un segundo túnel, con lo cual se podrá completar la doble vía de $205 \mathrm{~km}$, y la capacidad de transporte subirá a 40 millones de toneladas anuales. De allí en más, se incrementará el material rodante, hasta alcanzar la capacidad de 77 millones de toneladas (MZD 2011).

\section{CONCLUSIÓN}

En los últimos tres lustros, el proyecto de "resurrección" del Ferrocarril Trasandino movilizó a actores de distinta naturaleza: estatales y no estatales, nacionales y subnacionales. El crecimiento del nivel de actividad económica de los países de la región y los Acuerdos de Complementación Económica (ACE 16 y ACE 35) aumentaron el volumen del comercio a través de la cordillera de los Andes. En este contexto, se generaron las condiciones para pensar en la reactivación del servicio ferroviario. Pero junto con los incentivos, también surgieron los problemas.

Los principales obstáculos para la reactivación del Trasandino fueron el escaso interés del Estado nacional de Argentina y el contexto macroeconómico de este país, signado por una alta inflación, caída de la inversión extranjera, fuga de capitales y pérdida de la confianza debido a nacionalizaciones de empresas sin indemnización.

Ante la debilidad del Estado nacional, el proyecto fue liderado originalmente por la provincia de Mendoza, que operó como actor subnacional en un problema de transporte internacional. El Gobierno de Mendoza, durante la administración de Arturo Lafalla, puso en marcha una iniciativa, tendiente a reactivar el Ferrocarril Trasandino mediante alianzas con el sector privado, y con el apoyo de un grupo de profesionales contratados ad hoc por el Estado provincial. Los gobernadores siguientes mantuvieron la propuesta, para convertirla en política de Estado. El grupo operativo, conducido por el ingeniero Marcelo Rogé, estableció los lazos con actores argentinos y chilenos, estatales y privados, nacionales y subnacionales. De esta manera, Mendoza funcionó como líder del proyecto, realizando la tarea de actor subnacional, con capacidad de identificar y articular actores. Este proceso se perfeccionó con la Ley 24.482, por la cual el Estado nacional transfirió a la provincia de Mendoza la propiedad de la sección argentina del Ferrocarril Trasandino y la reconoció como actor subnacional.

La Ley 24.482 despertó grandes expectativas, en el sentido de empoderar a una provincia de frontera como actor subnacional, con capacidades para liderar el proceso de 
coordinación de actores involucrados, conciliar intereses y avanzar en la solución de los problemas de transporte internacional. El momento de tratamiento de esa ley en el Congreso argentino no fue favorable para el desarrollo de grandes debates parlamentarios, debido a la crisis económica nacional, lo cual invisibilizó un proceso de singular interés y proyección en favor de la integración latinoamericana. A ello se sumó la presión de las corporaciones militares que, mediante engaños y falsedades, indujeron al veto de la ley. Igual que en los gobiernos de facto de las décadas de 1950 y 1960, cuando frustraron la electrificación del Trasandino y la construcción de túneles largos de baja altura, las Fuerzas Armadas volvieron a movilizarse para obstaculizar esta línea ferroviaria y, en última instancia, para frustrar los procesos de integración entre los pueblos de la región y del desarrollo de los espacios de frontera. En los años 50 y 60 actuaron desde el poder, el cual controlaban mediante golpes de Estado y gobiernos de facto. En cambio, en 2001, las Fuerzas Armadas no impusieron su criterio desde el poder, sino mediante un lobby que les permitió obtener el veto presidencial a la Ley 24.472. De esta manera, los uniformados lograron anular -o reducir sensiblemente su capacidad operativa- al actor subnacional que lideraba la coordinación de acciones tendientes a la reactivación del Trasandino.

En la primera década del siglo XXI, el contexto macroeconómico de Argentina se tornó desfavorable para la captación de inversiones de largo plazo. El incremento de la inflación, la fuga de capitales y la nacionalización de empresas privadas sin indemnización configuraron un entorno poco amigable para grandes obras de ingeniería de montaña. Los sucesivos proyectos, elaborados por las empresas Tecnicagua primero y Corporación América después, no han logrado hasta el momento ponerse en marcha. De todos modos, el volumen del intercambio comercial a través de la cordillera de los Andes sigue aumentando, con lo cual, en un tiempo no muy lejano, es posible que estos proyectos se pongan en marcha. Entonces será preciso reconocer el papel que cupo al Estado provincial de Mendoza que, en calidad de actor subnacional, contribuyó a impulsar el proyecto, identificar actores, articularlos y liderarlos en función de un objetivo común.

\section{REFERENCIAS}

1. Argandoña, C y J. Poblete. 2010. "Las imágenes del proyecto que buscan unir Argentina y Chile por tren." La Tercera, 26 de diciembre. Santiago.

2. Balls, Gabriela. 2011. "Aseguran que en 2020 estará funcionando el tren trasandino." Los Andes, 7 de julio. Mendoza. 
3 Cámara de Senadores de la Nación. 2001. Transferencia de dos ramales ferroviarios a la provincia de Mendoza. Orden del Día No 861. 66 Reunión - 20 Sesión ordinaria - 23 de octubre de 2001. Versión taquigráfica. Disponible en http://www.senado.gov.ar/web/taqui/ taqui_op_adjunto.php?clave=F7388/231001.htm\#_1_228

4. Colacrai, Miryam. 2004. "La cooperación entre los actores subnacionales y el gobierno federal en áreas de frontera y en el desarrollo de la infraestructura física." Integración y Comercio 21:141-68. Consultado el 06 de marzo de 2013 (http://idbdocs.iadb.org/wsdocs/getdocument. aspx?docnum=33036381).

5. Cunietti, Emma. 1996. "La biblioteca popular de Potrerillos.” Pp. 108-9 en Luján y su gente, compilado por P. Lacoste. Mendoza: Diario UNO.

6. Decreto 1.491, Buenos Aires, 21 de noviembre de 2001. Boletín Oficial. Buenos Aires, 23 de noviembre de 2001.

7. Devés, Eduardo. 2003. El pensamiento latinoamericano en el siglo XX. Tomo II: Desde la CEPAL al neoliberalismo (1950-1990). Buenos Aires: Biblos.

8. Fontaine, Ernesto R. 2008. Evaluación social de proyectos. México: Pearson-Prentice Hall.

9. Galak, Oliver. 2008. “Avanza el proyecto del tren trasandino del grupo Eurnekian.” La Nación, 4 de septiembre, Buenos Aires. Consultado el 30 de septiembre 2010 (http://www.lanacion.com.ar/nota.asp?nota_id=1046375)

10. Guiñazú, Ricardo. 2001. Carta del coronel Ricardo Guiñazú al ingeniero Marcelo Rogé. Mendoza, 22 de noviembre. Copia en poder del autor.

11. Lacoste, Pablo. 1998. Grandes obras de Mendoza. Aportes para el estudio de la historia de la ingeniería y el turismo, con especial referencia al corredor andino. Mendoza: Diario UNO.

12__ 2000. El Ferrocarril Trasandino. Santiago: DIBAM/Editorial Universitaria.

13. Lafalla, Arturo. 2010. Utopía y realidad. Testimonio de un gobernador (1995-1999). Mendoza: EDIUNC.

14. Maira, Luis, ed. 2010. La política internacional subnacional en América Latina. Buenos Aires: El Zorzal.

15. Ministerio de Defensa de Argentina. 2001a. Expediente 1383/2001. República Argentina. 
16. _ 2001b. Memorándum de la Coordinación de Inmuebles. Dirigido a la Subsecretaria de Coordinación del Ministerio de Defensa, Dirección de Construcciones del Estado Mayor General del Ejército. Expediente 1383/2001 F. 13. Buenos Aires, 15 de noviembre de 2001.

17.—. 2001c. Carta del comodoro Flores a Alberto García. Expediente 1383/2001, F. 12. Buenos Aires, 23 de noviembre de 2001.

18. MDZ. 2011. "Cristina Kirchner recibió el proyecto final del Corredor Bioceánico Aconcagua." MDZ online 26 de julio, Mendoza, Argentina. Disponible en http://www.mdzol.com/mdz/nota/313829cristina-kirchner-recibio-el-proyecto-final-del-corredor-bioceanico-aconcagua/

19. Rodríguez, Eduardo. 2006. Chile, país puente. Santiago: RIL Editores.

20. Rogé, Marcelo. 2006. Proyecto de reactivación del Ferrocarril Trasandino Central. Informe de avance de trabajos. Mendoza: Ministerio de Ambiente y Obras Públicas (Mimeo).

21.Thomson, Ian. 1997. Los ferrocarriles y su contribución al comercio internacional. Buenos Aires: BID-INTAL.

22—. 2001. Los beneficios privados y sociales de inversiones en infraestructura: una evaluación de un ferrocarril del siglo XIX y una comparación entre ésta y un caso del presente. Santiago de Chile: CEPAL. Consultado 6 de marzo de 2013 (http://www.eclac.org/publicaciones/ xml/1/7031/LCL1538-P-E.pdf).

23. Thomson, Ian y Dietrich Angerstein. 1997. Historia del Ferrocarril en Chile. Santiago: DIBAM.

24. Zubelzú, Graciela. 2008. "Los gobiernos subnacionales en el escenario internacional: conceptos, variantes y alcances. Un marco de análisis para las acciones de las provincias argentinas." Pp. 19-45 en Las provincias argentinas en el escenario internacional. Desafíos y obstáculos de un sistema federal, editado por E. Iglesias. Buenos Aires: PNUD-CARI. Consultado el 06 de marzo de 2013 (http://www.cari.org.ar/pdf/provincias-escenario.pdf). 